to run in very slowly, so that the process occupies at least five minutes. In from ten minutes to a quarter of an hour later anæsthesia is complete, and the catheter is withdrawn. An operation lasting one and a half to two hours may now be performed without a further administration. Should the patient become at all cyanotic, or his breathing laboured, a catheter is passed into the rectum and 60 c.c. of the fluid allowed to escape, on which he rapidly returns to normal. When the operation is completed the fluid remaining in the rectum is removed by re-introducing the catheter and, if necessary, employing some form of suction apparatus,

The method proved an ideal one in most of the writer's cases. In one or two, however, it had to be supplemented by a small quantity of chloroform given in the ordinary way, and he has not usually found it satisfactory in children.

Thomas Guthrie.

\title{
REVIEW.
}

The Diseases of the Nose, Throat and Ears of Children in Daily Practice. By Prof. Dr. F. Goppert. Berlin: v. Springer. Pp. 166.

The title will probably at once raise the question in the minds of most as to the necessity for such a treatise, all the more so as it forms a special volume in the " Encyclopædia of Clinical Medicine." It is certainly difficult to realise that there is so much peculiar to children in aural and naso-pharyngeal ailments as to warrant a special work on the subject, and one's opinion will not probably be affected after reading this book. Those general practitioners who are not overcome by the terrifying series of maladies here described as affecting the child's nose, throat or ears, may easily slip into the error of thinking that they possess special knowledge of pathology and treatment of these parts, if they happen to overlook the occasional warning that under such and such conditions the case should be handed over to the aurist or rhinologist. This is the result of the vade mecum style on which the book is arranged, though this is more or less concealed by lengthy descriptive efforts. For instance, under "Naso-pharyngitis in Infants at the Breast," to which over thirty pages are devoted, there is a special chapter on the "Constitutional Effects of Naso-pharyngitis"; under this again there are other headings, the first mentioned being naso-pharyngitis and the nervous system, and finally this is divided into the subsections loss of rest, loss of appetite, habit spasm, to the first two of which are attached clinical notes of cases to illustrate the condition. On the other hand, the chapter on "Surgical Treatment of the Complications of Middle-ear Suppuration" describes polypi, mastoid disease, extradural abscess, sinus thrombosis, brain abscess and labyrinth disease, all within a page and a half! And one breathes a sigh of relief to find here a suggestion that treatment for these conditions should be confined to the aural surgeon.

It may be uncharitable to judge the work with no knowledge of the rest of the series of which it forms a part, but taken itself anyway it cannot be recommended either for purposes of reference or as a practical guide.

A. R. Tweedie.

\section{NOTES AND QUERIES.}

Dr. John Macintyre, of Glasgow, has been promoted a Knight of Grace of the Grand Priory of the Order of the Hospital of St. John of Jerusalem in England. 


\section{GENTRAL LONDON THROAT AND EAR HOSPITAL GRAY'S INN ROAD (Near King's Cross Stations).}

he work carried on at this Hospital comprises:

\section{The Daily Out-Patient Olinio.}

The Medical Officers attend as follows:

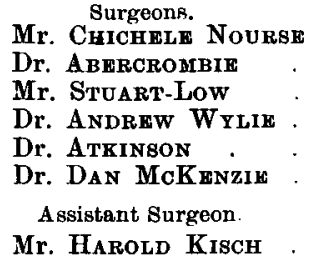

Out-Patient Clinic. Wednesday, at 2 p.m. Thursday, at 2 p.m. Saturday, at 2 p.m. Monday, at 2 p.m. Tuesday, at 5 p.m. Friday, at 5 p.m.
In-Patient Operations.

Friday, at 2.15 p.m.

Wednesday, at 2.15 p.m.

Monday, at 2.15 p.m.

Tuesday, at 2.15 p.m.

Thursday, at 2 p.m.

Thursday, at 4 p.m.

Mr. Harold KIsch $\cdot \cdot\left\{\begin{array}{c}\text { Monday and } \\ \text { Thursday }\end{array}\right\} a t 2$ p.m.

2. The Minor Operations.

These are performed at 9 a.m. on Monday, Tuesday, Wednesday, Thursday, Friday.

3.

\section{The In-Patient Department. Major Operations.}

These take place at 2 o'clock on Monday, Tuesday, Wednesday, Thursday, Friday.

The list of operations is to be seen on the notice board in the Out-patient Consulting Room

\section{Lectures and Demonstrations.}

Courses of Practical Instruction are given throughout the year by Members of the itaff, on Tuesdays and Fridays, at 3 p.m. punctually.

The Courses consist of two classes twice a week devoted to Anatomy, Pathology, Diagnosis ind Treatment of the special diseases dealt with at the Hospital. They may be joined at any ime.

A Surgical Anatomy and Operative Surgery Class is held when desired. The teachng is practical and demonstrative, and is illustrated by diagrams, models, specimens and nstruments.

\section{5.}

\section{The Pathological Laboratory}

Is at all times available to students. Dr. Wyatt Wingrave, Pathologist to the Hospital, $\$$ in attendance daily at 3 p.m.

\section{Glinical Assistants}

Are appointed from among those gentlemen who have enrolled themselves for attendance on he practice of the hospital.

Further particulars may be had on application to the Dean.

\section{Fees.}

Course of Practical Instruction ...

" " with attendance at Clinics 2 guineas.

ior attendance on the practice of the Hospital (Clinical Assistants)-

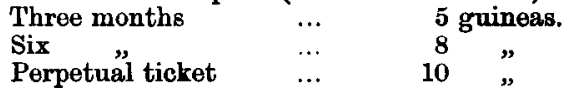

Clinical Assistants are admitted to the Practical Course Free.

$$
\text { WYATT WINGRAYE, K.D., }
$$$$
\text { Dean. }
$$

RICHARD KERSHAW, Secretary Superintendent. 


\section{WRIGHT, Publishers, BRISTOL.}

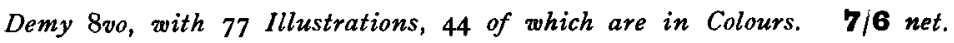

\section{THROAT, Diseares of the

\section{Fon Practitioners and Students.}

By W. G. PORTER, H.B., B.Sc., F.R.C.S.Ed.,

Surgeon to the Eye, Ear, and Throat Infirmary, E,tinburgh; Surgeon, Ear and Throat Department, Royal Hospital for Sick Children, Edinburgh; Aurist to the Fdinburgh Royal listitution for the Education of the Deaf and Dumb.

"The author's main object has been to provide the practitioner and serious student with a single volume of moderate size, embracing sufficient information on the diseases of the throat, nose, and ear, to be of value in practice. We may say at once that he has attained his object." - British Medical fournal.

"Eminently suited to the purpose for which it is designed."-Fournal of Laryngolngy.

" Eminently suited to the purpose for which it is designed."-Fournal of Laryngolngy. literature has evidently been laid under contribution. "It is well printed and well illustrated." -Lancet.

"The work is eminently suited to the purpose for which it has been designed. . a large amount of well. digested and accurate information has been packed into a surprisingly small compass. Special attention has been given to diagnosis, and to such treatment as can be carried out successfully by one who is not a specialist. . . We congratulate Dr. Porter upon producing a very excellent small manual."-Practitioner.

Originally published in 1912, the first Large Edition was exhausted in six Months.

The Second Impression was quickly sold out, and the Third Issue is now ready.

Demy 8vo. 1030 pages. With 16 Coloured Plates and over 200 Illustrations in the Text. Bevelled Boards, Burnished Top. $\mathbf{3 0} /$ net.

\section{AN INDEX OF DIFFERENTIAL DIAGNOSIS OF MAIN SYMPTOMS By Many Writers.}

Edited by HERBERT FRENCH, M.A., M.D.Oxon., F.R.C.P.Lond.

"May be said to represent the last word as to limits of diagnostic power . . . illustrations are of a uniformly high merit, and aid materially. Oof Dr. French's work, both as editor and contributor, we cannot speak too highly. This remarkable index." -British Medical Journal.

"All that it is possible to learn of medicine in its various branches outside the wards of a hospital will be found in this book."-Practitioner.

6th Edition. I 3 th Thousand. Completely Revised, with additional Articles and Illustrations. Demy 8vo. I056 pages. Bevelled Boands, Burnished Tops. 21/-net.

\section{AN INDEX OF TREATMENT}

By 83 Representative Contributors.

Edited by ROBERT HUTCHISON, M.D., F.R.C.P., Physician to the London Hospital.

A Complete Guide to Treatment in a Form Convenient for Reference.

"The editors and publishers may be congratulated on the production of a work of reference which we can cordially recommend to all busy practitioners."-British Melical fournal.

"The book is of special use to the general practitioner, who will ind in it many valuable suggestions for the management of disease." L Lancet.

"Handy, accurate. . . easy of reference. . . we congratulate editors and contributors upon having added to medical literature a useful and comprehensive work." -Medical Press and Circular.

Now Ready. Fourth Edition. Fully Revised. Crown 8vo. 9/6 net. With Diagrams of Surface Markings.

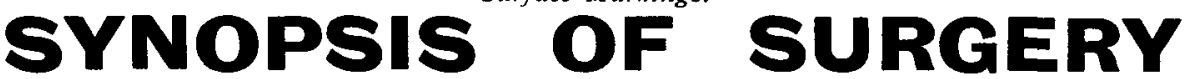

Fon Students and Practitioners.

By ERNEST W. HEY GROYES, M.S., M.D., B.Sc.Lond., F.R.C.S.Eng.

". - appears to contain all that is necessary in a synopsis, and . . . is not too condensed. . . may be legitimately employed for revising knowledge." - Lancet.

"The additions necessary to keep it quite up to date have been freely made.. . . Among the best of its kind, and the author is to be congratulated on its readableness, its lucidity, and its fulness-notable qualities." British Medical Journal.

Bristol JOHN WRIGHT \& SONS, Limited.

London: SIMPKIN, MARSHALL, HAMILTON, KENT \& Co., Ltd. 


\section{Mayer \& Meltzer's New Introductions.}

\section{An Improved Ether Apparatus for Use in Nose \& Throat Operations.}

Devised by RAYMOND E. APPERLY, M.R.C.S.Eng., L.R.C.P.Lond., Assistant Anæsthetist to Middlesex Hospital.

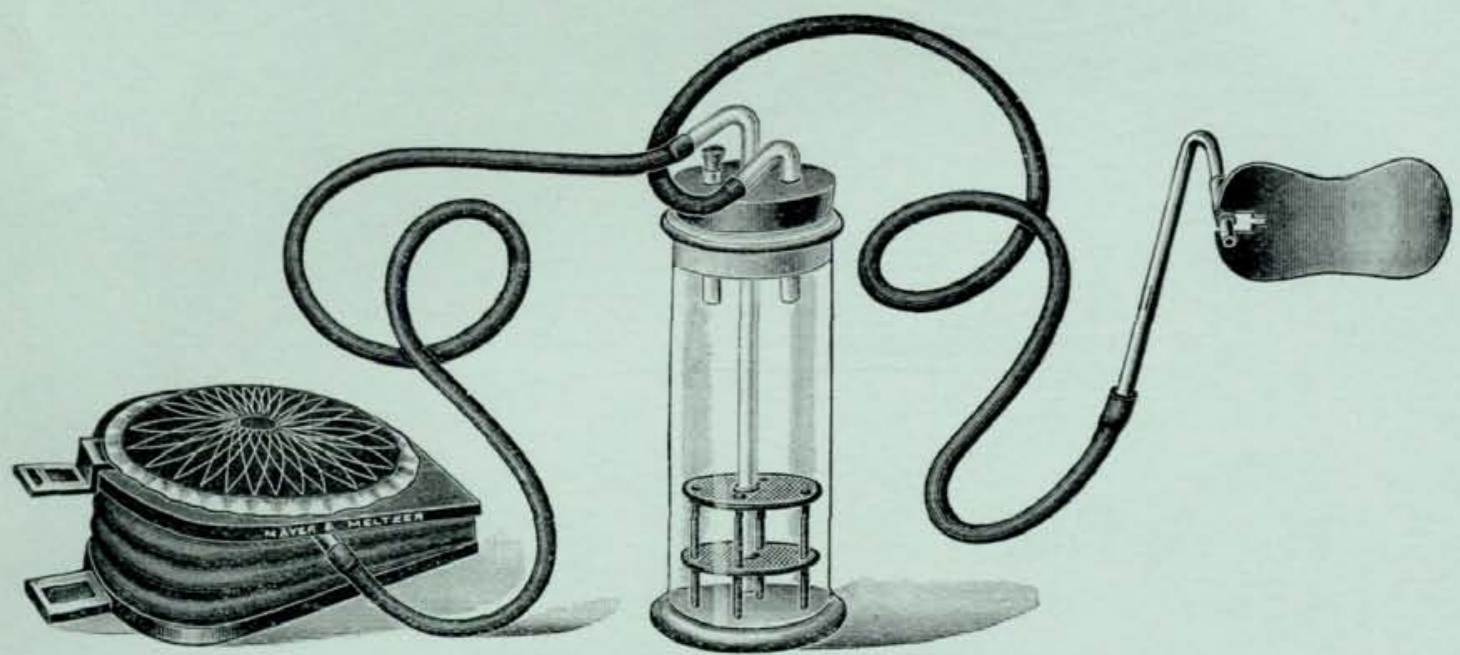

Extract from Paper by Raymond E. Apperly and Somerville Hastings. Vide Lancet,

September 20, 1913.

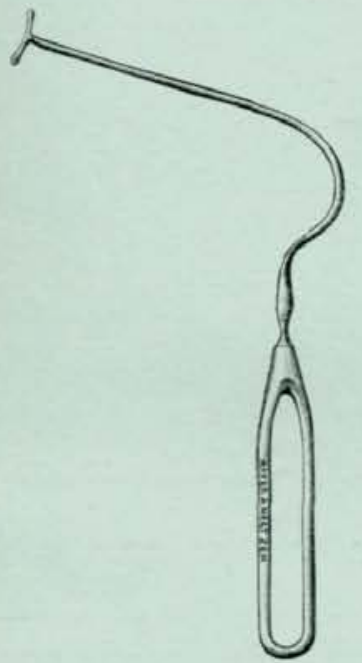

A Tonsil Probe. By H. Tilley, F.R.C.S.

A Septum Needle. By H. LUND, M.B., F.R.C.S.Eng.

An Improved Gag. By W. S. KERR, M.B., F.R.C.S.Edin.

Instruments of Intra=Nasal Dacryocystotomy.

A Posterior Rhinoscope. By W. LLOYD, F.R.C.S.

An Eustachian Bougie with Sliding Scale.

By W. H. KELSON, M.D., F.R.C.S.Eng.

An Antrum Punch. By Seymour jones, F.R.C.S.

"Emandem" Improved High Efficiency

Examination Lamps, etc., etc.

MAYER \& MELTZER, 71, GT. PORTLAND STREET, LONDON.

Branches: MELBOURNE; CAPETOWN; JOHANNESBURG. 


\section{MAYER \& MELTZER,}

Surgical Instrument Makers.

ESTABLISHED OVER FIFTY YEARS.
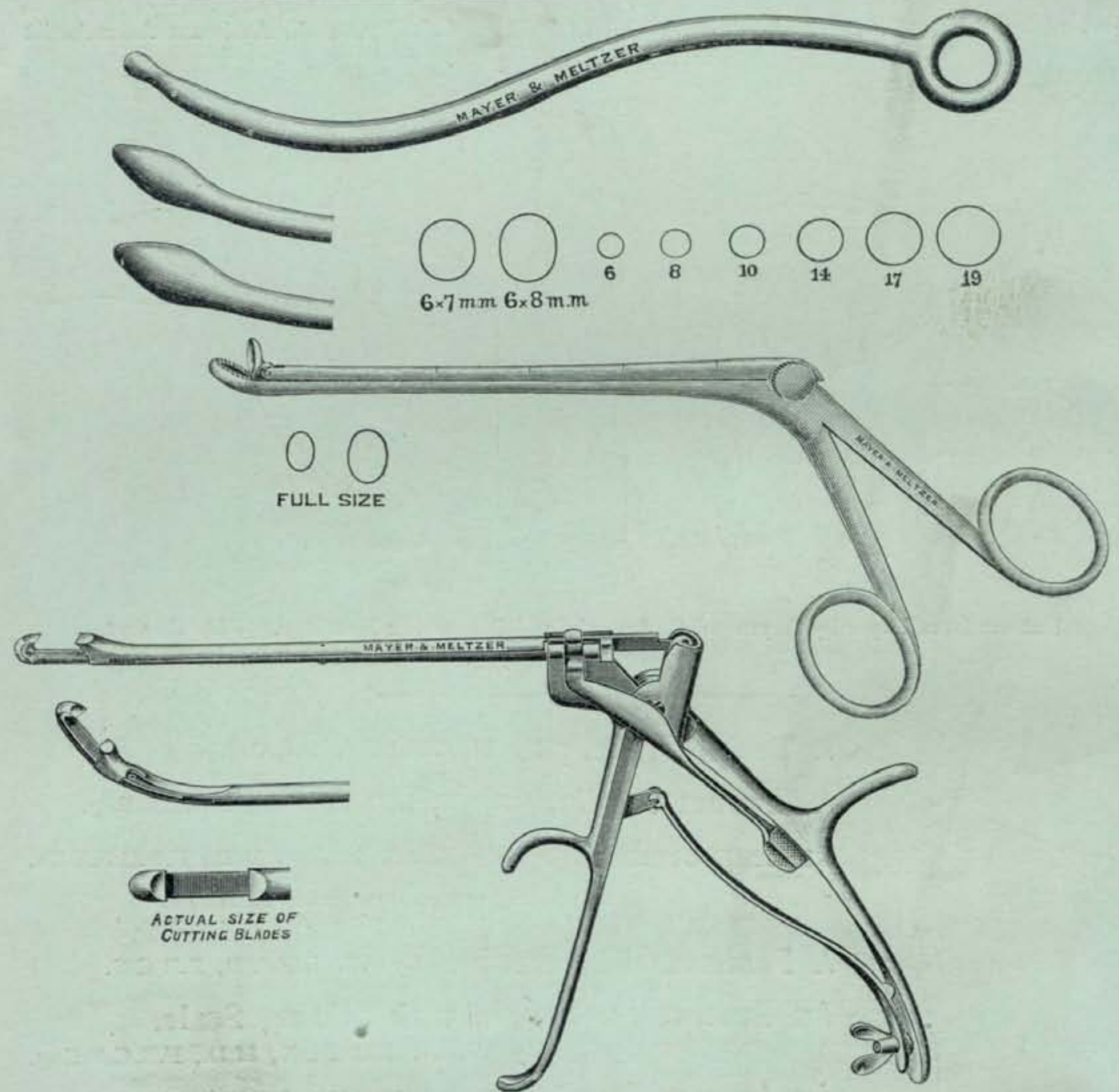

Instruments as used by Dr, Watson-Williams for the Intra-Nasal Operation for Frontal Sinus Suppuration.

(SEe JOURNAL OF LARYNGOLOGY, May, 1914.) Full Particulars on application.

MAYER \& MELTZER, 71, GREAT PORTLAND ST., LONDON.

Branches: MELBOURNE; CAPETOWN; JOHANNESBURG. 